Günter Jerouschek

\title{
Des Rätsels Lösung? - Zur Deutung der Hexenprozesse als staatsterroristische Bevölkerungspolitik*
}

\author{
Alfred Lorenzer zu seinem 65. Geburtstag \\ am 8. April 1987 gewidmet
}

Die Hexenverfolgungen, die sich, wohl im Gefolge des aufbruchhaften Klimas der 68er-Bewegung, einer anhaltenden wissenschaftlichen Konjunktur erfreuen, sehen sich einem neuen, denkwürdigen Deutungszusammenhang ausgesetzt, seit Gunnar Heinsohn und Otto Steiger, beides Hochschullehrer an der Universität Bremen, Sozialwissenschaftler der eine, Ökonom der andere, 1979 mit ihrer zentralen These, Adel und Geistlichkeit hätten zu Beginn der Neuzeit in einer konzertierten Aktion die Hexenmassaker inszeniert, um das im Schwange befindliche Geburtenkontrollwissen namentlich der Hebammen zu liquidieren, aufwarteten ${ }^{1}$. Eine breitere deutsche Öffentlichkeit wurde auf die These angelegentlich einer Titelgeschichte des Nachrichtenmagazins $>$ Der Spiegel ${ }^{2}$ i 984 aufmerksam, die sich auf eine weitere Publikation der Autoren nämlichen Inhalts bezog3. War nun schon die SpiegelGeschichte durch sinistre Unzulänglichkeiten in der Vertrautheit mit dem bewährt salopp aufbereiteten Gegenstand gezeichnet, so konnte man auch den genannten Publikationen Heinsohns und Steigers bis dahin schwerlich den Eindruck abgewinnen, die Geschichte würde den Autoren den Gefallen tun, sich ihrer These, die Hexenprozesse atmeten den Geist polit-strategischer Zweckrationalität, zu fügen. Man durfte nunmehr gespannt sein, ob die zuletzt vorgelegte »ausführliche Erklärung " (Heinsohn/Steiger I98 $_{5}$, I $_{3}$ ) dazu angetan sein würde, die Argumentationsdefizite zu beheben.

Gespannt sein durfte man um so mehr, als man bei der Befassung mit einem so komplexen Sujet wie den Hexenprozessen allemal Gefahr läuft, jenen drei Vierteln an literarischer Produktion aufzusitzen, die, wie dies unlängst wieder angemerkt wurde, getrost » wieder vergessen werden ${ }^{4}$ können und die vorliegende Publikation Ende 1985 bereits die fünfte Auflage erlebte, womit sie zu einem der seltenen wissenschaftlichen Bestseller reüssierte, wie sie sich auch einer wachsenden akademischen Reputation erfreut.

In der Tat bereitet die Deutung des Phänomens der Hexenprozesse nicht geringe Schwierigkeiten. So ist es mit der gängigen fortschrittsevolutiven Geschichtsauffassung kaum verträglich, daß die Hexenverfolgungen erst in der frühen Neuzeit, im I6. und namentlich 17.Jh., zu ihrer vollen Blüte fanden, und eben nicht im Mittelalter, wohin die noch heute stehende Rede sich Mißliebige zu wünschen pflegt, um sie dort verbrannt zu wähnen - ein beredtes Zeugnis für die Verdrän-

* Zugleich Besprechung von Heınsohn, Gunnar; Steiger, Otco: Die Vernichtung der wessen Frauen. Hexenverfolgung, Menschenproduktion, Kinderwelten, Bevölkerungswıssenschaft, Herbstein 1985 (März).

I Heınsohn, Gunnar; Knıeper, Rolf; Steiger, Otto: Menschenproduktıon - Allgemeine Bevölkerungstheorie der Neuzeit, Frankfurt a. M. 1979. Zu weiteren Publikationen der These vgl. Heinsohn/Steiger 1985,11 .

2 Der Spiegel, 38.Jg., Nr. 43, 1984, $117 \mathrm{ff}$.

3 Heinsohn/Steiger 1984 .

4 Schott 1982, $68 \mathrm{f}$. 
gungsleistung, die Hexenverfolgungen aus der Neuzeit zu verbannen. Die ältere Forschung um die Jahrhundertwende, repräsentiert etwa durch Hansen's oder Soldan/Heppe ${ }^{6}$, wußte sich dementsprechend nicht anders zu behelfen, als in den Pogromen das Aufgehen einer noch mittelalterlichen Saat zu konstatieren oder sich in konfessionellen Schuldzuweisungen zu ergehen, wenn sie sich nicht, wie teilweise auch die neuere Forschung, damit begnügte, die geistigen Waffen vor der Ungereimtheit, daß Zeitläufte von jenen schauerlichen Pogromen überschattet wurden, wo - Renaissance, Humanismus, Reformation - längst das Licht der Vernunft gegen so paranoide wie barbarische Irrationalismen, wie sie in den Hexenprozessen zutage traten, hätte feien müssen, zu strecken?.

Erwies sich darin aber augenfällig die begrenzte Reichweite ideengeschichtlicher Ableitungen, so war es nur konsequent, wenn sich, nicht zuletzt unter dem Einfluß des anfangs der 7oer Jahre einsetzenden frauenemanzipativen Engagements, die Fragestellung zu wandeln begann und Versuche unternommen wurden, die Hexenprozesse gerade unter der Prämisse ihrer frühneuzeitlichen Bedingtheit zu verstehen $^{8}$.

$\mathrm{Da}$ in diesem Zusammenhang die verfolgten Hexen auch ein verführerisches Identifikationspotential abzugeben vermochten, das sie dem freien Spiel feministischer Assoziationskräfte aussetzte, bis hin zu phantastischen Szenarien nachfahrender mondsüchtiger Frauen, die naturverwoben orgiastischen Drogenkulten oblagen, soll nicht verschwiegen werden. Zwar ist die diesbezügliche Polemik Schormanns ${ }^{9}$ in ihrer Pauschalität überzogen, doch erweist der Obskurantismus der angesprochenen idealisierenden Mythologisierungstendenzen, zumal wenn von jeglicher Quellenkenntnis unangefochten, der eigenen Sache einen schlechten Dienst, verstellt er

5 Hansen 1900, 1901.

6 Soldan/Heppe: Geschıchte der Hexenprozesse (ed. Max Bauer), Bd. 1, 2; Hanau o. J. Nachdruck der Ausgabe 19 II $^{3}$

7 So vernachlässigen die Vorauflagen von Soldan und Heppe kurzerhand die von protestantıscher Seite durchgeführten Pogrome, in der irrtümlichen Annahme, der Hexenwahn eignete alleın dem katholischen Naturell. Umgekehrt versteht sich die von Diefenbach 1886 veröffentlichte Gegenschrift darauf, den Katholizısmus von der Verantwortlichkeit weitestgehend freizusprechen, um nur zweı Beispiele zu nennen. Die von Midelfort $1972,33,350$ erstellten Statıstiken scheınen ummerhın eme höhere Verfolgungsintensität auf katholischer Seite nahezulegen, doch krankt diese, auch von Delumeau i98 8 , Bd. 2 , 530 geteilte Ableıtung daran, daß die absoluten Zahlen alleın in Korrelatıon zur Gesamtbevölkerung aussagekräftıg wären, worüber uns aber die Kenntnisse fehlen. Auch ist keıneswegs ausgemacht, daß eine kürzere Verweildauer in den Verliesen bis zur Aburteilung auf eine gelindere Gangart schließen ließe, ındem auch die gegenteilige Auffassung plausibel zu begründen wäre. Und sollten Heınsohn/Steıger 1985 , 13 Delumeau zu den +Verrätslern` des Phänomens der Hexenverfolgungen zählen, so gilt immerhın zu berücksıchtıgen, daß Delumeau eıne Fülle von Anregungen gibt, der "Lösung des historıschen Rätsels« (Delumeau 1985, Bd. 2, 537) auf die Spur zu kommen.

8 An Veröffentlichungen wären hier etwa zu nennen Honegger 1978, mit enner Textauswahl neuerer Forschungsansätze oder Becker et al. 1977.

9 Schormann 1981, 119 an die Adresse Honeggers gerichtet, vgl. Anm. 8. Mag man seiner Krutik an der Weigerung, "Akten zu lesen (ebd.) noch nachfühlen können, so kann man kaum Verständnıs dafür aufbringen, daß er die Konzentration der Forschungsbemühungen auf die Frau geißelt: Rekrutıerten sıch die Opfer der Hexenverfolgungen, wie Schormann 1981, 116f. selbst konstatiert, zu ca. $80 \%$ aus Frauen, so wird es der Frauenbewegung kaum zum Vorwurf gereıchen können, wenn sıe ihr Hauptaugenmerk auf dieses viktımologische Faktum nuchtet. Auch gestattet die Vielfalt der angebotenen Erklärungen, anders als Schormann 198I, 123 polemısch nahelcgt, noch lange nıcht, sıch über eıne Erklärungspflicht überhaupt erhaben zu wähnen, so als schwinde mi der Anzahl mehr oder wentger plausibeler und i.E. wıdersprüchlicher Erklärungsmodelle die Erklärungsbedürftigkeıt. Dabeı erwıes sıch für Teile der Frauenbewegung namentlich der Versuch von Margaret Murray 1921, 1962 ${ }^{2}$ als attraktiv, in den Opfern der Hexenverfolgungen Angehörıge eınes seıt der Antike überkommenen Fruchtbarkeıtskultes auszumachen. War jedoch schon die Quellenauswertung fragwürdig, so steht ener solchen These auch das bekanntgewordene Archıvmaterıal in eıner solch überwältıgenden Fülle entgegen, daß sie mit Fug ad acta gelegt werden kann; zwar gelang Ginzburg 1980 mıt den Benandantı für Frıaul der Nachweıs eınes Kultes, der freilich mit dem von Murray postulierten wenig gemein hat, doch legen die von ihm mitgeteilten Befunde so gut wie keınerleı Zusammenhänge mit der sonst gängıgen Prozeßpraxis nahe. 
doch gerade dic Sicht auf die reale historische Dramaturgie, die hinter den Hexenprozessen obwaltet: daß nämlich so gut wie keines der in die Mühlen der Hexenjustiz geratenen Opfer irgendeine der Handlungen, derentwegen es dann verurteilt und verbrannt wurde, in Wirklichkeit begangen hatte. Was die Verfolgungsrelevanz des Hexereikonzeptes anlangte, so ist hierfür zuvörderst auf dessen Ausprägung in den Köpfen der Strafverfolgungsorgane abzustellen, regelmäßig der das Gewaltmonopol exekutierenden studierten Juristen also, die in Sachen Hexerei zugleich ermittelten und richteten.

In dieser >Personalunione von Staatsanwalt und Richter, in der sich Verfolgungsund Verurteilungsinteresse paarten, liegt sicher bereits ein Grund für den furchtbaren Aburteilungsautomatismus, den das inquisitorische Strafverfahren der frühen Neuzeit - an sich ein Meilenstein auf dem Fortschritt zu einer rationaleren Organisation der Strafrechtspflege - zeitigte. Jedenfalls waren auf der Grundlage des überkommenen Anklageverfahrens, in dem der zivilistischen Gepflogenheit entsprechend ein Kläger den von ihm Beklagten der geziehenen Straftat zu überführen hatte, widrigenfalls ihm selbst Sanktionen drohten, Hexenverfolgungen größeren Ausmaßes gar nicht denkbar, wie auch aus den Anfängen der Hexenprozesse erhellt, wo unter dem Primat des Anklageprozesses obrigkeitliche Inquisitionen nur ausnahmsweise und in außerordentlichen Fällen betrieben wurden ${ }^{10}$.

So hat man Fug dafürzuhalten, der Hexenprozeß habe zwar den Inquisitionsprozeß als bereits bekannt und geübt vorausgesetzt, ihm jedoch erst zu dessen letztendlicher Durchsetzung als ordentliches strafrechtliches Prozedere verholfen. Die Hexenprozesse waren also gleichsam die Feuerprobe für die Effizienz des neuen inquisitorischen Disziplinierungsinstrumentariums, die es - wir dürfen sagen: mit Bravour - bestanden hat. Angesichts solcher strafrechtsgeschichtlicher Spezifika ist es zu bedauern, daß der Ertrag aus juristisch versierter Feder zur Aufhellung des Phänomens der Hexenverfolgungen kaum mehr als eine quantité négligeable abgibt - ein exemplarischer Beleg für die unlängst als grundsätzliches Manko monierte Selbstbeschneidung strafrechtlichen Forschens ${ }^{11}$. Die Hinterfragung des von Stolleis hierfür als verantwortlich ausgemachten strafrechtswissenschaftlichen Selbstverständnisses - wir dürfen hinter ihm mit Fug auch eine korrespondierende Fremderwartung annehmen -, das sich in einer "rechtspolitischen Zuliefererfunktion zum geltenden Strafrecht " $^{\prime 2}$ erschöpft, ist freilich überfällig, soll die Disziplin in die Lage versetzt werden, wie in der anstehenden Frage, Antworten darauf zu finden, unter welchen Bedingungen Rationalität, namentlich auf dem Sektor der Verbrechensbekämpfung, dysfunktional und kontraproduktiv auszuufern droht: eine Fragestellung von unabweisbarer Aktualität, die kaum ins Raritätenkabinett der Historie abgetan werden kann, mag man auch über deren Salonfähigkeit ${ }^{13}$ uneins sein.

Für Heinsohn und Steiger stellt sich diese Frage leider nicht. Anhand des geschilderten Spektrums des Forschungsstandes bestimmen sie ihren eigenen Standort derge-

10 Dem widersprechen auch nicht die beı Unverhau in: Degn et al. ( $\mathrm{Hg}$.) 1984, 59 ff. mitgeteilten Befunde, da hser der Anklageprozeß längst nıcht mehr in seiner ursprünglich gehandhabten Form in Erscheinung tritt und bereits deutlich von der Inquisıtionsmaxıme überlagert 1st. Die sıch auf Schmidt 1941 stützende Ansicht der Autorın, Inquisitionsprozeß und Folter in Deutschland entbehrten kanonisch- oder römıschrechtlicher Anleihen, vgl. a.a.O., 73, ist freilich dahıngehend zurechtzurücken, daß nıchts dagegenspricht, daß beı beidem die geıstliche Gerıchtsbarkeıt Pate gestanden hätte, vgl. Trusen 1962, $7 \mathrm{f}$.; 1984 oder Kroeschell $1973,233$.

i $\mathrm{Vgl}$. Stollers 1985,259 .

12 Ebd.

13 Hierın sıeht jedenfalls Schott 1982, $68 \mathrm{f}$. eınen Grund für die nachhaltıgen und der Bedeutung des Themas völlig zuwiderlaufenden Berührungsängste, deren Überwındung sıch allmählich abzuzeıchnen scheint. Jedenfalls gibt die Akzeptanz, die der Münchener Dissertation von Michael Kunze 1981 zuteil wurde, zu dieser Hoffnung Anlaß. 
stalt, daß sie die bisher konkurrierenden Ansätze gegeneinander auszuspielen trachten: Werde einerseits der Grund für die Hexenverfolgungen in der Ausschaltung weiblicher Irrationalität durch männliche Rationalität gesucht, so besage die ältere und keineswegs überwundene Forschung das glatte Gegenteil, daß nämlich erst der Durchbruch des rationalen Weltverständnisses den Prozessen ein Ende bereitet habe (Heinsohn/Steiger $1985,14,25$ ). Dem stellen sie nun ihre eigene These gegenüber, daß nämlich »die neuzeitliche Hexenverfolgung als Nebenprodukt der Geburtenkontrollbekämpfung " (Heinsohn/Steiger $1985, x_{3}$ ) aufzufassen sei, womit die etablierte Hexenforschung »die furchtbare Rationalität der keineswegs wahnsinnigen Hexenjäger « (Heinsohn/Steiger 1985, 14) verfehle.

Die Polemik gegen sämtliche Forschungsansätze, die die Hexenverfolgungen als Kehrseite eines einseitigen Primats der Ratio zu verstehen suchen, läßt freilich aufhorchen und weckt den Verdacht, daß die Autoren den Standpunkt einer Unteilbarkeit des Intellekts verfechten - so als wäre die >Dialektik der Aufklärung ${ }^{14}$ nie geschrieben worden und hätte nicht gerade die jüngste Vergangenheit zu Genüge vor Augen geführt, daß wissenschaftliche Großtaten und intellektuelle Befähigung noch lange nicht die Gewähr dafür bieten, sich nicht zugleich barbarischen Ideologien verschreiben zu können.

Indes erhärtet sich der Verdacht, für Heinsohn und Steiger sei die Anerkennung einer Zwieschlächtigkeit der Ratio ein Unding, mit fortschreitender Lektüre, wie denn auch nicht von ungefähr Wissenschaftler psychoanalytischer Provenienz, die sozusagen von Hause aus den Darbietungen des Verstandes weniger mit Hochachtung als vielmehr mit geradezu professionellem Mißtrauen zu begegnen pflegen, den besonderen Unmut der Autoren auf sich ziehen.

So vermeinen Heinsohn und Steiger beispielsweise, der Frankfurter Sozialpsychologe und Psychoanalytiker Alfred Lorenzer habe sich sozusagen schon selbst disqualifiziert, indem er bei Jean Bodin eine Befangenheit im Hexenwahn diagnostiziere $^{\mathrm{s}}$ : Jean Bodin - gleichzeitig ein Protagonist der Hexenverfolgungen wie eine wissenschaftliche Kapazität der frühen Neuzeit, u.a. Begründer der Souveränitätslehre - sei nämlich Kritikern des Hexenwahns gegenüber - speziell dem Arzt Johann Weyer, der in seiner 1563 veröffentlichten Schrift >De praestigiis daemonum $<$ hinter den vorgeblichen Hexenkünsten mehr melancholische Einbildung als den Teufel am Werk sah - »keineswegs als gestörte Persönlichkeit, sondern mit dem Spott des souveränen Wissenschaftlers « (Heinsohn/Steiger 1985, 25) aufgetreten. Dies genügt nun Heinsohn und Steiger, Bodin von der ihm durch Lorenzer bescheinigten Wahnbefangenheit freizusprechen - so als gehörte nicht zum klinischen Bild des Paranoikers, diejenigen für gestört zu halten, die den eigenen Wahn nicht teilten.

Angesichts eines solchermaßen eklatanten Mangels an Argumentationsstringenz im Umgang mit abweichenden Ansichten müssen sich die Autoren erste Zweifel an der wissenschaftlichen Seriosität ihres Unternehmens gefallen lassen; der geharnischte Vorwurf an die Adresse psychoanalytisch orientierter Deutungsversuche, sie besagten weher etwas über die Schwierigkeiten der Autoren mit ihrem Thema als über die Hexenverfolger selber « (Heinsohn/Steiger 1985, 25), fä]]t jedenfalls allemal auf die Verfasser selbst zurück.

Die Triftigkeit ihrer These einmal unterstellt, es walte »politische Rationalität hinter diesen Massakern « (Heinsohn/Steiger 1985, I3) und es sei die Einschätzung von einer Wahrhaftigkeit der Hexenverfolgungen nur dann aufrechtzuerhalten, »wenn

14 Horkhemer/Adorno 1969.

is Lorenzer 1984, 41 f. Daß die Exekutıon des Wahns in praxı sodann von ausgefeiltester Präzısıon seın mag, sel unbestritten. 
man ganz unverstellt und zahlreich aufgeschriebene Motive der Hexenverfolger ausblendet " (Heinsohn/Steiger 1985, 30), so müßte sich der >Hexenhammer der Predigermönche Institoris und Sprenger - noch vor Bodins ,Démonomanier die »Zentralschrift zur Anleitung der Verfolgung (Heinsohn/Steiger 1985, 14) - eigentlich wie eine aufgeklärte Instruktion zur Unterbindung der Geburtenkontrolle lesen. Und wirklich gewinnt man aus der eklektischen Zusammenstellung der Zitate den Eindruck, als wäre es den beiden Dominikanern allein um Empfängnisverhütung und Abtreibung durch Hebammen zu tun.

Um es vorwegzunehmen: Dem ist keineswegs so. Der 'Malleus Maleficarum‘, in dem erstmals durch eine konsequente Sichtung die disparaten Äußerungen insbesondere kanonischer Autoritäten zu Fragen der Dämonologie in ein kohärentes Hexereikonzept überführt wurden, strotzt nur so von kolportierten Greuelmärchen wie Hexenflügen, Tierverwandlungen, geschlechtlichem Umgang mit Dämonen oder obskuren Schadenszaubereien.

Freilich ist nicht zu verkennen, daß auch die Tabu-Sphäre der Sexualität und in deren Gefolge Impotenz, Empfängnisverhütung, Bewirkung von Fehlgeburten und Abtreibung oder Kindsopferungen einen diskursiven Angelpunkt abgeben; doch ist dies wenig verwunderlich, wenn man berücksichtigt, daß es Sprenger und Institoris darauf ankam, ihr Konstrukt autoritativ abzusichern: Die problematische Stellung der Sexualität im kirchlichen Lehrgebäude und namentlich in der monastischen Tradition sowie die hervorragende Bedeutung der impotentia ex maleficio, der angezauberten Zeugungsunfähigkeit, im kanonischen Scheidungsrecht - letzteres bot Gewähr für eine durchgängige Abhandlung durch die kanonistische Kommentarliteratur - bescherte den Autoren des >Hexenhammers ein so willkommenes wie respektables Fundstellenreservoir. Nicht von ungefähr kommen im rechtspraktisch maßgeblichen 3. Teil des >Hexenhammer Empfängnisverhütung und Abtreibung kaum mehr zur Sprache.

Ähnliches gilt von der Bulle `Summis desiderantes affectibus< Innozenz' VIII. von ${ }_{14} 8_{4}$, die von Sprenger und Institoris zur Unterstützung ihres inquisitorischen Engagements gegen Hexen bei der Kurie erwirkt worden war und zu der der >Hexenhammer gleichsam einen Kommentar darstellt: Auch hier suggerieren Heinsohn und Steiger, die Bulle beschränke sich auf die Ausrottung empfängnisverhütenden Wissens (Heinsohn/Steiger 1985, 33), was gleichfalls den Tatsachen nicht gerecht wird, da Teufelsbuhlschaft und Schadenszauber noch vor der Empfängnisverhütung rangieren ${ }^{16}$.

In besonderem Maße augenfällig wird die verkürzende Betrachtungsweise von Heinsohn und Steiger anhand ihres Umgangs mit dem canon >si aliquis` (= X 5. I 2.5) aus den 234 erlassenen Dekretalen Papst Gregors IX., der sedes materiae des kanonischrechtlichen Verbots der Empfängnisverhütung, wobei schon der angebotene Herkunftsnachweis, der bei Burchard von Worms haltmacht (Heinsohn/ Steiger 1985 , I I 2 ), unzulänglich ausfällt ${ }^{17}$.

I6 Am einfachsten zugänglich ist der Wortlaut der Bulle ım Vorwort zu der Übersetzung des Malleus Maleficarum< durch Schmidt, hier in der Ausgabe München $1983^{1}$, XXXIr ff. Wer will, darf auch aus Sprengers fanatıscher Marienverehrung Rückschlüsse auf die Natur semnes Geıstes und semne Eingenommenheit für die Hexenverfolgungen ziehen. Der von sexualpathologischen Phantasien, 1.d.R. von Kastrationsängsten diktıert, durchtränkte ,Hexenhammer<, sst in dieser Hinsıcht ohne Vorbild.

17 Raymund von Penıafort, der mit der Redaktıon dieser frühen Kodifikatıon betraut war, hatte den Passus Buch 17 der $>$ Decretorum libri vigintı Burchards von Worms vom Beginn des I I. Jhs. entnommen, wo er als Wormser Synodalbeschluß ausgewıesen war. Allein war man damıt einer Fälschung aufgesessen, denn ein derartiger Beschluß exıstıert nıcht. Als Urheber kommt hıngegen Regino von Prüm ın Betracht, dem, en Jahrhundert vor Burchard, woht eine korrumpierte Fassung des römıschen Rechts, konkret der Paulussentenzen aus der Lex Romana Visıgothorum, zur Textgrundlage gedient hatte, vgl. Reginonıs 
In inhaltlicher Hinsicht ist der Passus insofern denkwürdig, als er die Empfängnisverhütung durch magische oder sonstige Mittel zur Tötung aufwertete und damit einen Fremdkörper im kanonischen Recht darstellte, das grundsätzlich auf dem Standpunkt der Sukzessivbeseelung stand und Empfängisverhütung wie Abtreibung als Eheverfehlung betrachtete und erst die Abtreibung eines beseelten Fötus dem Tötungsverbot unterfallen ließ ${ }^{\mathrm{r}}$. Aus dem Leitsatz zu dieser Bestimmung >Homicida est qui facit vel dat sortilegia, vel venena sterilitatis nun schließen Heinsohn und Steiger auf das rechtsgeschichtliche Novum »der Gleichsetzung von >Zauberei mit Empfängnisverhütung und ihrer Qualifizierung als Mord « (Heinsohn/Steiger I 985 , I I 2), was, träfe dies zu, der von den Verfassern vertretenen These fraglos sehr entgegenkommen würde.

Allein, auch hier versagen sich die historischen Fakten dem gewünschten Ergebnis, indem diesmal eine unzutreffende Übersetzung zur Untermauerung der Zentralthese herhalten muß: Zwar ist die von Heinsohn und Steiger angebotene Übertragung »Wer Zauberei verübt oder sterilisierende Gifte verabreicht, ist ein Mörder « (Heinsohn/Steiger 1985 , I I 2) vom Wortlaut her denkbar, doch läßt die Formulierung des caput, das durch den Leitsatz zusammengefaßt werden sollte, keinen Zweifel daran, daß ssterilitatis sowohl auf ssortilegia wie auch auf >venena< zu beziehen ist. M.a. W. werden also mitnichten Zauberei an sich und Empfängnisverhütung in einen Topf geworfen, wie Heinsohn und Steiger vorgeben, sondern ist allein die Empfängnisverhütung in unterschiedlichen Ausführungsmodalitäten geregelt, wovon auch der $>$ Hexenhammer wie selbstverständlich ausgeht ${ }^{19}$

Prumıensıs Abbatis De Ecclesıasticıs et Religione Chrıstıana Librı Duo, Liber II, 89. In: Patrologia Latina (ed. Migne) 132, Sp. 301 . Rekurriert wird auf die Sentenz 5, 23, 14, die im Corpus Jurıs Civilis als D. $48,19,38$, 5 in der Lex Romana Visigothorum als $5,25,8$ erscheint, vgl. die Edition von Haenel 1849 Grundsätzlich war im römıschen Recht nur die Abtreibung gegen den Willen des Vaters strafbar, ohne daß der Schwangeren oder dem Fötus irgendwelche Rechte zugekommen wären. Die vorliegende Bestummung stellte ausnahmsweise auch die Abgabe von Aphrodislaca und abtreibenden Drogen unter Strafe, aufgrund der befürchteten Gefährlichkeıt mit Magie in Verbındung gebrachter Drogen für Leib und Leben. Eine erhöhte Strafandrohung betraf den Fall, daß der Gebrauch zum Tod führte. Die von Regıno hıraus abgeleıtete Einschätzung der Empfängnısverhütung als Totschlag freilich war durch nichts gerechtfertigt.

I 8 Die sog. Sukzessıvbeseelung war arıstotelischen Ursprungs und besagte, daß Im Zuge der fötalen Entwıcklung verschiedene Beseelungsstufen durchlaufen würden, bis der Fötus mit der sanıma ratıonalis‘, der Geistseele begabt würde. Hatte schon Arıstoteles in der Erlangung des Empfindungsvermögens eine Grenze für die Abtreibung sehen wollen, so umso mehr die jüdisch-christliche Tradition, als die Septuagintaübersetzung des Alten Testaments ins Grechische, vom Ursprungstext abweichend, enne Abtreibung von dem Zeitpunkt an als Totschlag dem Jus Talionıs unterfallen ließ, da der Fötus menschlich gestaltet erschien. Im Einklang mit der arıstotelischen Embryologie wurde also auf die organmorphologische Ausdifferenzıerung abgestellt, woraus für das Abtreibungsrecht eıne Art Frıstenlösung resultıerte. Diesen Standpunkt teilte auch das kanonısche Recht, vgl, Im Decretum Gratıanı C. 32 q. 2 c. 8 oder in den Dekretalen X 5.12.20. Alleın komplizierte sich dieser Rechtskomplex nıcht nur durch die angesprochene Aufwertung der Empfängnisverhütung zur Tötung, wodurch vorderhand enne Strafbarkeıtslücke entstand, da die Abtreibung eınes unbeseelten Fötus eben kejne Tötung darstellte, sondern vor allem durch die völlig ungekJärte Fristentermunierung: Bestand noch $1 \mathrm{~m}$ wesentlichen Einıkeıt darüber, daß der weibliche Fötus später als der männliche beseelt würde, so variierten die angenommenen Frısten beträchtlich, je nachdem, ob man sıch auf pseudoarıstotelische oder hippokratısche Terminierungen berıef oder sıch die alttestamentarıschen postnatalen Reınıgungsvorschriften zu eıgen machte, die einer Frau nach der Geburt eines Knaben 40, nach der eines Mädchen 80 Tage auferlegte. Daß letztere Lösung in die Glosse zum Decretum Eingang fand, konnte nichts an der heillosen Konfusion in dieser Frage ändern.

$19 \mathrm{Vgl}$. um >Hexenhammer Pars I 9.8, in der Schmidtschen Übersetzung S. I 3 if. Von außerordentlicher Tragwette auch für die Theoriebildung Heinsohns und Steigers ist in diesem Zusammenhang, wie die in Anm. I 8 angesprochene Strafbarkeıtslücke rechtstechnısch bewältıgt wurde: Es war von Begınn an unstreıtıg, daß die dekretıerte Aufwertung der Empfängnısverhütung zur Tötung alleın ım Bereıch des forum internum, der Versündigung, zum Tragen komme, dagegen keinerlei Auswirkungen in weltlicher Hinsicht entfalte. Die Aufwertung betraf also lediglich die Beıcht- und Bußpraxıs, ließ aber die weltliche Rechtspflege unberührt, was schon Raymund von Penıafort in seıner Beichtsumme außer Zweifel stellte, vgl. Raymundus de Penıafort: Summa de Poentrentıa Liber II, Tit. I $₫ 6$, in der Ausgabe 1603,123 . Dies bleibt bes Heinsohn und Steiger außer Betracht. 
Nun wird, wer sich selbst schon der nämlichen Verführung wie Heinsohn und Steiger ausgesetzt sah, einer wissenschaftlichen Entdeckung zuliebe vorliegende Daten und Befunde nach Möglichkeit pro domo in Beschlag zu nehmen, bis zu einem gewissen Grad Verständnis für dadurch bedingte Fehlleistungen aufbringen. Doch gerät es dort an seine Grenze, wo die kritische Distanz zum abzuhandelnden Gegenstand insoweit aufgehoben erscheint, daß Informationen, die den eigenen Geniestreich in Frage zu stellen drohen, kurzerhand und unhinterfragt mit schnöder Geste vom Tisch gewischt werden.

Die sich abzeichnende Wahrnehmungsfragmentierung scheint auch für die Großspurigkeit der Polemiken verantwortlich zu sein, mit der Vertreter abweichender Ansichten, heißen sie nun Foucault, Elias oder Lorenzer (Heinsohn/Steiger 1985, I I , I73, 24), abgekanzelt werden, so als hätte die Hexenforschung sich überwiegend aus Ignoranten rekrutiert, bis Heinsohn und Steiger es beschieden war, im >Hexenhammer die Schöpfung eines souveränen Geistes zu entdecken. Zwar schwant den Autoren, »daß die erhaltenen Prozeßakten das Motiv der Geburtenkontrollauslöschung weniger deutlich zum Ausdruck bringen « (Heinsohn/Steiger 198 , 147), als ihrem Konstrukt zuträglich ist - im Mittelpunkt steht dort durchweg das $>$ maleficium $<$, der durch zauberische Praktiken angerichtete Schaden an Mensch, Tier und Feldfrüchten -, doch wird dieses gewichtige Kontraindiz mitnichten zum Anlaß genommen, das eigene Theoriegebäude zu hinterfragen; stattdessen wird großzügig zugestanden, daß dieser Umstand u.a. wenigstens die bisherigen "Schwierigkeiten eines zureichenden Verständnisses« (ebd.) erklärt, seitens der etablierten Hexenforschung, versteht sich. Wodurch wurden nun Heinsohn und Steiger in die glückliche Lage versetzt, die Rechtswirklichkeit, die, soweit sie sich uns aus den Archivbeständen erschließt, ihrer These zuwiderläuft, als trügerisch zu entlarven? - Die Antwort ist umwerfend einfach: des Pudels Kern sei eine dürftige Quellenlage, womit die Heinsohns und Steigers These dienstbaren Archivalien entweder abgegangen sein müssen oder Aktenvorgänge, die die These gestützt hätten, erst gar nicht angelegt worden wären (ebd.), wie denn überhaupt das Augenmerk auf die prozeßanleitende Literatur zu richten sei (Heinsohn/Steiger 1985, 148), die der These mehr entgegenkomme.

Damit nicht genug, gerät bei Heinsohn und Steiger die ganz grundsätzliche Erwägung zu einem Dilemma der Hexenverfolger (Heinsohn/Steiger 1985, 146), nicht der eigenen Theoriebildung, daß es sich nur schlecht mit der für die Hexenverfolger in Anspruch genommenen Zweckrationalität vertragen will, wenn zig-tausende die Schätzungen gehen bis in die Millionen - von Frauen auf den Scheiterhaufen landeten, ausgerechnet um die Reproduktion der Bevölkerung anzuheizen.

Fällt es dem unbefangenen Leser schon schwer, den zweckrationalen Impetus von Hexenbulle und ,Hexenhammer nachzuvollziehen, so betraf dies allem Anschein nach nicht weniger auch Zeitgenossen von Sprenger und Institoris: Georg Golser jedenfalls, Bischof von Brixen, als solcher einer der von Heinsohn und Steiger für die Exekution der neuen bevölkerungspolitischen Devise der Liquidation des Geburtenkontrollwissens in Anspruch genommenen Protagonisten, zeigte sich seltsam unbeeindruckt von der beschworenen Zweckrationalität des mit der Hexenbulle gewappneten Institoris, als dieser mit seinen neu gewonnenen Erkenntnissen über das Hexenwesen dem Domkapital aufwartete. Im Gegenteil wähnte der Oberhirte deutliche Anzeichen von Verkalkung im Gebaren des Inquisitors und wies ihn mit der Bemerkung unnachsichtig aus seinem Sprengel hinaus: »er bedunkt mich propter senium ganz kindisch sein worden, als ich in hie zu Brixen (Juli 1485) gehort hab cum capitulo «20.

$20 \mathrm{Vgl}$. das Vorwort zur ,Hexenhammer--Übersetzung von Schmidt, S. XVI. 
Nach Heinsohns und Steigers Rationalitätsthese müßte nun gerade das Verhalten Golsers eher auf geistige Verwirrtheit schließen lassen, es sei denn, die Einsicht in den rationalen Gehalt des `Hexenhammer`wäre erst späteren Generationen aufgegangen. Dann wiederum hätten die kritischen Schriften eines Weyer oder von Spee, die beide den Hexenverfolgungen immerhin während ihrer Blütezeit entgegentraten, für Ausgeburten des Irrationalismus zu gelten, wo bislang Spees, Cautio Criminalis< etwa für eines der spärlichen Zeugnisse praktischer Vernunft gewürdigt wurde, in einem Zeitalter, wo der Verstand spazieren ging, wie dies ein Chronist, dessen Frau ein Opfer der Verfolgungen geworden war, auszudrücken wußte ${ }^{2 x}$. Ob Heinsohn und Steiger ihre These bis hin zu solchen nur mehr absonderlichen Konsequenzen ausgelotet haben, steht dahin. Fest steht hingegen, daß, nächst den Hexenverfolgern, Heinsohn und Steiger die einzigen sind, die von der ungebrochenen "Rationalität der keineswegs wahnsinnigen Hexenjäger (Heinsohn/Steiger 1985, I4) überzeugt waren, resp. sind.

Nach dem Gesagten kann es nicht mehr überraschen, wenn den Autoren verschlossen bleibt, inwieweit die mißlichen Erfahrungen Institori(s) gelegentlich seiner ersten Inquisitionsversuche gegen Hexen für die Konzeption des `Hexenhammer mit ausschlaggebend gewesen sein dürften: Wenn der dritte Teil des `Hexenhammer fraglos von dem Interesse diktiert ist, das Hexenwesen auch als Gegenstand der weltlichen Gerichtsbarkeit auszuweisen, so ist dies, nachdem Institoris mit seiner Kampagne bei der geistlichen Gerichtsbarkeit mehr als kläglich gescheitert war, ein nur zu verständliches Unterfangen. In diesem Interesse ist auch der tiefere Grund zu suchen, weshalb es Sprenger und Institoris darum zu tun war, mit den ihnen zu Gebote stehenden scholastischen Argumentationstechniken gegen überkommene und durchaus respektable Gelehrtenmeinungen anzuschreiben, denenzufolge die Zauberwerke in Wirklichkeit lediglich durch teuflische Machenschaften ins Werk gesetzte Verblendungen, also Einbildungen seien. Bei den Doctores beider Rechte galt nämlich als ausgemacht, daß grundsätzlich erst der Eintritt eines konkreten Schadens die volle Härte der weltlichen Gerichtsbarkeit auf den Plan rief ${ }^{22}$.

Handelte es sich mithin bei der Zauberei um ein scrimen mixti fori<, ein Mischdelikt, das im Rahmen einer Art konkurrierender Gerichtsbarkeit dem Zugriff der geistlichen wie der weltlichen Strafgewalt offenstand, so verstand sich der dritte Teil des 'Hexenhammer dezidiert als prozessuale Handlungsanleitung auch an die Adresse der weltlichen Strafrechtspflege, um eine möglichst umfassende Verfolgung des von Sprenger und Institoris ersonnenen Delikts zu gewährleisten. Wenn also die Autoren des >Hexenhammer auf die Realität des Schadenzaubers abhoben, so hatten sie damit den Angelpunkt der weltlichen Zugriffsmöglichkeit im Auge und demzufolge nichts weniger als die von Heinsohn und Steiger unterstellte säuberliche Trennung von faulem und richtigem Zauber (Heinsohn/Steiger 1985, 27f.) oder gar die Ausgrenzung der Hexerei aus dem Kontext des gängigen Aberglaubens und der Ketzerei (Heinsohn/Steiger 198 5, 26). Vielmehr erfuhr der Aberglauben eine massive Intensivierung, indem, was ehedem für phantastisches Blendwerk oder Hirngespinst galt, bei Sprenger und Institoris zur schieren Realität geriet. Dabei hatten sie umso

2I Weng, 42, 60; gemünzt war die Äußerung auf die Nördlinger Hexenprozesse anfangs der goer Jahre des 16. Jhs.

22 In aller Deutlichkeit kommt diese gemeinrechtliche Positıon beispielsweise in der Carolina zum Tragen, deren Art. 109 die Vollendung des Zaubereidelikts vom Eintrıtt ennes konkreten Schadens abhängıg machte: m. a. W. war die Zaubere als gegen Sachen, Leib oder Leben gerichtetes Delikt ausgestaltet. Die Peınliche Gerichtsordnung Kaiser Karls V. von 1532 ist am leıchtesten in der Reclam-Ausgabe von Radbruch und Kaufmann $1975^{4}$ zugänglich. 
mehr Anlaß, auf der Realität dieser Erscheinungen zu insistieren, als sogar das kanonische Recht den Irrglauben an nachtfahrende Weiber für anstößig befand ${ }^{23}$. Ebensowenig geht es an, aus der Diskriminierung des Glaubens an die Hexerei unter Karl d.Gr. kurzerhand auf eine Billigung der Geburtenkontrolle schließen zu wollen (Heinsohn/Steiger I985, 230f.) oder das archivalisch überlieferte >Raden und Segensprechen` mit Wissen um Schwangerschaftsverhütung und Geburtenkontrolle gleichzusetzen (Heinsohn/Steiger 1995, 156), indem gewissermaßen unterstellt wird, was zu beweisen gewesen wäre, daß, wenn von Zauberei die Rede sei, dies allemal eine "Chiffre« (Heinsohn/Steiger 1985, 44) für Geburtenkontrolle darstelle.

Nicht zuletzt steht und fällt die These, die Hexenprozesse würden allein als Nebenprodukt der Geburtenkontrollbekämpfung adäquat erfaßt, auch mit der Triftigkeit des rechtsgeschichtlichen Befundmaterials, das Heinsohn und Steiger zugunsten ihrer Ansicht ins Feld führen: Es ist also beispielsweise zu fragen, ob, wie die Verfasser vorgeben, wirklich I 507 mit der Constitutio Criminalis Bambergensis "die welthistorisch neuen Todesstrafen für Hexerei bzw. Geburtenkontrolle (Heinsohn/Steiger 1985, I I5) Einzug gehalten und durch deren Übernahme in die Constitutio Criminalis Carolina, die Peinliche Gerichtsordnung Kaiser Karls V. (PGO) von I 532, "Gültigkeit für den größten Teil des Kontinents« (Heinsohn/ Steiger 1985 , i I 5 ) erhalten haben. Schon aus der Lektüre der Vorrede zur Carolina hätten sich Heinsohn und Steiger Gewißheit darüber verschaffen können, daß beide Rechte in der ihnen beigelegten Intention von Grund auf verkannt werden: Nichts lag ihnen ferner, als neues Recht zu setzen, wurde doch gerade die mangelnde Vertrautheit der Rechtsprechung im Heiligen Römischen Reich mit »vnsere Keyserliche recht $^{24}$ - gemeint war das geltende römische Recht - als Motiv dafür genannt, dessen maßgebliche Grundzüge auf „eyn begrieff ${ }^{25}$ bringen zu lassen. Sichergestellt sollte durch die Abfassung werden, daß das strafrechtliche Prozedere im Reich den "gemeynen rechten ${ }^{26}{ }^{6}$ gemäß erfolgte, um so Rechtsmißbräuchen, namentlich der exzessiven Folterjustiz, entgegenzuwirken. Ihrem Selbstverständnis entsprechend wollte die Carolina mithin nicht mehr sein als ein Grundriß, eine Art gemeinrechtlicher Leitfaden für die deutsche Strafrechtspraxis.

Im angesprochenen gemeinen Recht wiederum fand sich die dem zeitgenössischen mos italicus entsprechende Zusammenschau der mittelalterlichen Version des rezipierten römischen Rechts und des kanonischen Rechts verkörpert. Und wie nicht anders zu erwarten, kehren in Bambergensis und Carolina die von Heinsohn und Steiger als rechtsgeschichtlich gleichsam revolutionäres Novum ausgegebenen Bestimmungen schlicht in der Diktion wieder, die ihnen schon im römisch-kanonischen Recht zuteil geworden war. Der für den angesprochenen Komplex beispielsweise einschlägige Art. I 33 PGO, der Empfängnisverhütung und Abtreibung der belebten Leibesfrucht mit dem Tod ahndet, im Falle der Abtreibung einer nicht lebendigen Leibesfrucht indes von der Todesstrafe absieht und des Strafmaßes

23 Es handelt sıch um >cepıscopı^, C. 26 q. 5 c. I 2 im Decretum, eın Steın des Anstoßes für die Protagonısten des Hexenmusters, die alle ihnen zu Gebote stehende Rabulistik darauf verwandten, den Canon aus der Welt zu argumentieren. Teils wurde schlicht darın auf Abhilfe gesonnen, daß die erst neuerdings in Erscheinung getretene Form des Hexenwesens zum Zeitpunkt des Erlasses des Canons noch nucht existent gewesen sei.

24 Vgl. Radbruch/Kaufmann 1975, 27. Zugrunde liegt die Vorstellung, mit der stranslatio imperii, dem Übergang des römıschen Reıchs an das fränkısch-deutsche Kaisertum seı auch das Recht der römıschen Kaıser überkommen, untermauert durch die erste Mitte des 17. Jhs. widerlegte Legende, Lothar III. habe seine förmliche Approbation verfügt.

25 Radbruch/Kaufmann 1975, 28.

$26 \mathrm{Ebd}$ 
halber die Einholung eines juristischen Gutachtens anordnet, schreibt exakt den Rechtszustand fest, wie er sich seit alters im gemeinen, römisch-kanonischen Recht herausgebildet hatte: die Todesstrafe auf die Empfängnisverhütung entsprechend den Dekretalen Gregors IX., dem sog. Liber Extra, die Differenzierung in der Abtreibungsbestrafung entsprechend den sonstigen Bestimmungen des kanonischen Rechts, im Einklang mit der seit Accursius gefestigten Kommentierung des Corpus Juris $\mathrm{Civilis}^{27}$. Mit anderen Worten: Das bei Heinsohn und Steiger welthistorische Novum war in Wirklichkeit ein alter Hut.

Auf einen vergleichbaren Mißgriff verfallen Heinsohn und Steiger bei dem Versuch, die kirchenstrafrechtlichen Novellierungen des Verbots der Empfängnisverhütung und der Abtreibung durch die Päpste Sixtus V. und Gregor XIV. ausgangs des I6. Jhs. für ihre These zu vereinnahmen: Ist den Verfassern darin noch zu folgen, daß der Novelle Sixtus' V. I 588 , die eine drastische Verschärfung des bisherigen Rechtszustandes zum Inhalt hatte, indem die überkommene Fristenlösung im Bereich des Abtreibungsverbots verworfen und für Abtreibung und Empfängnisverhütung unterschiedslos die Todesstrafe angedroht wurde, angesichts ihrer in Ansätzen bevölkerungspolitischen Motivierung epochemachende Bedeutung zukommt ${ }^{28}$, so verkennen sie jedoch, daß der Reformpapst, einer der ersten ökonomisch planenden Realpolitiker auf dem Heiligen Stuhl, seiner Zeit damit hoffnungslos voraus war. Daß die Zeit für die angestrebte Reform noch nicht reif war, ersieht man am besten daraus, daß die sixtinische Reformgesetzgebung bereits I 59 I unter Gregor XIV. ${ }^{29}$ wieder rückgängig gemacht wurde. Wenn nun Heinsohn und Steiger vorgeben, die Rückkehr zum vorsixtinischen Rechtszustand habe »nichts an der moralischen Gleichstellung von Verhütung und Tötung " (Heinsohn/Steiger 1985, 332, Fn. 297) ändern wollen, so haben sie damit Kenntnis von Motiven, die Gregor selbst verborgen geblieben wären: Die Aufhebungsverfügung jedenfalls verweist im Hinblick auf die neuerliche Novellierung ausdrücklich auf die intendierte Entkriminalisierung von Empfängnisverhütung und Abtreibung, um den Gläubigen die Rückkehr in den Schoß der heiligen Mutter Kirche nicht zu erschweren, zumal die verschärften Sanktionen die in sie gesetzten kriminalpolitischen Hoffnungen nicht erfüllt hätten ${ }^{30}$. Das Corpus Juris Canonici verblieb fortan - wenn auch nicht 'perpetuo<, auf ewig, wie von Gregor dekretiert, so doch für die folgenden drei Jahrhunderte - bei der gemeinrechtlichen Fristenkonzeption, bis sich I 869 Pius IX. und 1917 auch das kanonische Recht auf die sixtinische Reformgesetzgebung zurückbesannen, womit die katholische Kirche $z$. T. bis ins 20. Jh. über das weltweit liberalster Abtreibungsrecht verfügte. Hieraus dürfte zu Genüge erhellen, daß nicht etwa Ehmke die von Heinsohn und Steiger konstatierte »typische Verkennung dieser Position der Kirche ( (ebd.) zu verantworten hat, sondern vielmehr Heinsohn und Steiger selbst ${ }^{31}$.

Daß die Unterbindung eines vorgeblichen Geheimwissens um Empfängnisverhütung und Abtreibung längst nicht die brennendste Sorge war, die die politisch

27 Einem Redaktionsversehen ist es zuzuschreiben, wenn mißachtet wurde, daß die Qualifikation der Empfängnısverhütung als Totschlag bußsakramentaler Natur war. Accursius glossierte D. $47.11 .4 \mathrm{~mm}$

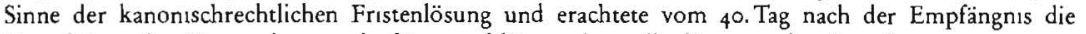
Grundsätze des Verwandtenmords für eınschlägıg, ohne allerdings in der Beseelungstermınıerung geschlechtsspezifisch zu differenzıeren.

28 Zum Wortlaut der Verfügung vgl. das ,Magnum Bullarıum Romanum،, T. 2, Lugdunı 1673, 640 f.

$29 \mathrm{Vgl}$. Anm. 28, a. a. O., 709. Gregor war 1. Ü. nicht der unmittelbare Nachfolger Sixtus' im Pontifikat.

30 Ebd. Hierbeı seı Heınsohn und Steıger zugute gehalten, daß sie mıt >moralischer Gleıchstellung، nıcht etwa die bußsakramentale Beurteilung der Empfängnısverhütung ım Auge hatten, denn diese war seit 1234 festgeschrieben und wurde weder durch die Novelle Sixtus noch die Gregors in irgendener Form tangiert.

$31 \mathrm{Vgl}$. Ehmke in: Arndt et al. 1979, $193 \mathrm{f} ., 206$. 
führenden Kreise in der frühen Neuzeit umtrieb, wird vollends unabweisbar, vergegenwärtigt man sich den zeitgenössischen juristischen Diskussionsstand, wie er sich bezüglich der rechtlichen Beurteilung von Empfängnisverhütung und Abtreibung darstellt: Gesetzt den Fall, die These Heinsohns und Steigers träfe zu, so ist schon nicht einzusehen, weshalb der vergleichsweise simple Zauberei-Art. Iog PGO $\mathrm{zu}$ einem juristischen Monstrum wie der Hexerei aufgebläht werden mußte, wo doch Art. I 33 PGO mit der Todesstrafe auf Empfängnisverhütung eine ungleich einfachere Handhabe bot, die Geburtenkontrolle zu eliminieren. Und von welchem Teufel mußten denn die Juristen der frühen Neuzeit, die doch die vornehmsten Agenten der neuen staatsterroristischen Bevölkerungspolitik hätten sein müssen, geritten sein, daß sie, und das gegen den eindeutigen Wortlaut von Art. 133 PGO, die Empfängnisverhütung von der dekretierten Androhung der Todesstrafe ausnahmen $^{32}$, teilweise gar die Totschlagsqualität der Abtreibung überhaupt leugneten und von der Todesstrafe absehen wollten ${ }^{33}$ ? So wurde beispielsweise bei der Neufassung von Art. 133 PGO durch die Kursächsischen Konstitutionen von 1572 die Empfängnisverhütung schon gar nicht mehr aufgeführt und die Abtreibung erst von der Schwangerschaftsmitte an als Totschlag gewürdigt, eine weitgehende Entschärfung der Abtreibungs-Strafbarkeit also, wo gleichzeitig der Hexereikomplex eine drastische Ausweitung erfuhr ${ }^{34}$. Und wie reimt es sich mit der These Heinsohns und Steigers zusammen, daß Thomas Sanchez SJ, der unangefochtenen moraltheologischen Autorität der frühen Neuzeit, nichts besseres einfiel, als auf der Grundlage der überkommenen Fristenlösung einen Indikationenkatalog zu entwickeln, der an ,Liberalität ‘ zugunsten der Schwangeren nicht nur für kirchliche Verhältnisse kaum mehr zu überbieten war ${ }^{35}$ ?

Desgleichen zeugt es nicht gerade von Kompetenz, wenn bei Heinsohn und Steiger die Bambergensis als Strafrecht »für das Deutsche Reich (Heinsohn/Steiger 1985 , I I4) figuriert, wo deren Geltungsbereich sich auf das Fürstbistum Bamberg beschränkte - was freilich deren Vorbildfunktion als smater Carolinaer keineswegs schmälern soll. Und auch die Carolina selbst hat in Ungarn, Sardinien, Sizilien, Neapel, Spanien oder gar Amerika, wohin Heinsohn und Steiger ihren Geltungsbereich ausdehnen (Heinsohn/Steiger I985, i I 5), nicht das geringste verloren; sie galt allein im Heiligen Römischen Reich Deutscher Nation und auch da nicht einmal vorbehaltslos, da die sog. ssalvatorische Klausels am Ende der Vorrede den Fortbestand territorialer Rechtsgewohnheiten gewährleisten mußte.

Auch waren die Verfasser nicht gerade gut beraten, wenn sie, um das Ausmaß des Terrors zu veranschaulichen, ausgerechnet die 20000 Todesurteile des sächsischen Juristen Benedikt Carpzov bemühen (Heinsohn/Steiger 1985 , I 38 ), wie dies auch der sSpiegel kolportiert und Carpzoy gar zum furchtbarsten protestantischen

32 Vgl. etwa Berlich: Quarta Pars Conclusıonum..., Conclusıo VIII, Nr. 57 f. Berlich 16283, 79. Im Wege dieser restriktıven Auslegung, die $1 \mathrm{~m}$ übrıgen h. M. war, wurde die in Anm. 27 angesprochene Fehlredaktıon in Art. 133 PGO bereınıt, womit sıch auch die weltliche Kommentierung den Standpunkt der Kanonistik zu eigen machte.

33 Diese Forderung auf der Grundlage der authentischen Version des römischen Rechts wurde von gemeinrechtlichen Autoritäten wie Jacobus Menochıus 1585, 503 erhoben.

${ }_{34} \mathrm{Zu} \mathrm{Empfängnısverhütung} \mathrm{und} \mathrm{Abtreibung} \mathrm{vgl.} \mathrm{die} \mathrm{Konst.} 4$ im 4. Teil 'Crımınalias. Die Hexere anlangend, wurde, über die Carolina hinausgehend, nucht allexn der Schadenszauber unter Strafe gestellt, sondern schon der Teufelspakt für sıch genommen mit dem Scheiterhaufen bedroht. Damıt überbot das protestantische Terrıtorıalrecht sogar den 'Hexenhammerc, dem es 1 mmerhın noch um die Realität des Schadens zu tun war. Das sächsısche Recht, dem im Zuge der Kommentierung durch Berlich und ınsbesondere Carpzov überregıonale Bedeutung zukam, vollzog damıt die Säkularısıerung bıs dahın geistlicher Kompetenzbereiche.

35 Vgl. Thomas Sanchez: Disputationum de Sancto Matrimonii Sacramento Tomı tres. T. 3. Antwerpiae $I_{6} I_{4}, 176 \mathrm{ff}$. Sanchez erweiterte auf thomıstischer Grundlage die bis dahın eher restriktıv gehandhabte medizınısche Indikatıonskasuıstik um einen ethıschen und sozıalen Indikationenkatalog. 
Hexenverfolger stempelt. Ist schon zu fragen, ob seinem Hauptwerk, der bis ins I 8. Jh. die deutsche Strafrechtspflege beherrschenden >Practica die zitierte Bezeichnung "Hexenhammer des Protestantismus « (ebd.) gerecht wird, so ist es ein nur mehr verdrießlicher Lapsus, wenn auch Heinsohn und Steiger der Legende von Carpzovs 20000 Todesurteilen aufsitzen: Carpzov war nämlich im Laufe seiner jahrzehntelangen Richtertätigkeit lediglich mit zwei Hexenprozessen überhaupt befaßt, die beide, da Carpzov die Voraussetzungen für eine peinliche Befragung verneinte, mit Freisprüchen endeten. Carpzov zählt damit zu den rühmlichen Ausnahmen innerhalb des an ifurchtbaren Juristen gewiß nicht armen Richterstandes im 17. Jh. Dabei hätte es nicht einmal abseitiger Fachliteratur bedurft, von diesem seit 1940 nachgewiesenen Faktum ${ }^{36}$ Kenntnis zu nehmen, der Blick in ein gängiges rechtsgeschichtliches Lehrbuch hätte genügt ${ }^{37}$.

Die angeführten Beispiele dürften nun hinlänglich ausgewiesen haben, daß die von Heinsohn und Steiger zur Fundierung ihrer These, die Hexenprozesse verstünden sich als ein zweckrational eingesetztes Instrument zur Ausmerzung des überkommenen Geburtenkontrollwissens, herangezogenen Befunde einer kritischen Überprüfung nicht standhalten. So patent es sich auch ausgenommen hätte, die solchermaßen instrumentalisierten Hexenprozesse in einem rationalistischen Geschichtskonzept unterbringen zu können - mit dem angebotenen Lösungsversuch jedenfalls sind Heinsohn und Steiger an diesem Vorhaben gescheitert. Die Forschung kommt nach wie vor nicht umhin, sich mit den Entstehungsbedingungen des Hexenwahns auseinanderzusetzen. In diesem Zusammenhang verdient angemerkt zu werden, daß ich mir wenig von der in jüngeren Forschungsbeiträgen verbreiteten Mode verspreche, in kulturrelativistischer Unvoreingenommenheitsmanier dem Terminus , Wahn abzuschwören ${ }^{38}$, als ob der Glaube an nächtlichen Ausfahrten auf Besen und Böcken, an orgiastische Hexensabbate und all die anderen Ingredienzen des Hexenkonzepts aufhöre, psychopathologischer Natur zu sein, wenn nur derlei Phantasmen sich zu einem kollektiven Syndrom auswüchsen.

Setzt man - um nur eine Entwicklungslinie herauszugreifen - die Hexenverfolgungen in Bezug zu der Ketzerinquisition der römischen Kirche, so fällt auf, daß sie einerseits den Endpunkt des institutionellen Tätigwerdens der Inquisition markieren, zum anderen mit den Hexen erstmals eine real nicht existierende sekte< zum Gegenstand ihres Berufsethos gerät, wobei Verbindungen zur praktisch gleichzeitig durch die Kurie verfügten Exilierung der spanischen Juden sowie der Inquisition der im Lande verbliebenen zwangskonvertierten Juden unter dem Vorwurf der Ketzerei greifbar sind. Hier könnte eine institutionsanalytische Deutung ansetzen, ausgehend von der mittlerweile geläufigen Erkenntnis, daß ein Strafverfolgungsapparat nicht zuletzt auch für seine viktimologische Klientel zu sorgen weiß.

Hierüber bleibt freilich darauf Bedacht zu nehmen, daß ideengeschichtliche Ableitungen aus den Inhalten der mittelalterlichen Theologie allzuleicht auf den Trugschluß einer kontinuierlichen Entwicklung verfallen und die Hochscholastik als Protagonistin der Hexenverfolgungen figuriert, wo doch vordringlich danach zu fragen wäre, unter welchen Bedingungen die marginalen Zugeständnisse etwa eines Thomas von Aquin, weit entfernt von einem dogmatisch formulierten Hexereikonzept, ausgangs des I 5.Jhs. als Eckpfeiler eines regelrechten Wahnsystems wieder-

36 Böhm 1940, 371 ff., 1941, 155 ff., 1942, 301 ff. Den Ursprung der Legende siehe be1 Oldenburger 1675, 816.

37 Vgl, nur Wieacker 1967,217. Das Besspiel legt auch nahe, daß die im Schwange befindlichen Schätzungen über die Gesamtzahl der Opfer der Hexenverfolgungen nach unten zu korrigieren sind, was den Pogromen freilich nichts von ihren grauenhaften Ausmaßen nımmt.

38 Vgl. etwa Stockinger in: Degn et al. (Hsg.) $1984,28$. 
kehren konnten. Dabei erscheint die Überbetonung des Teufels als Gegenspieler Gottes noch am ehesten einsichtig, als Ausdruck impliziter Selbstzweifel einer Kirche, die im Zeichen einer charismatischen Heilseinrichtung angetreten war, im Spätmittelalter aber nachhaltig die düsteren Züge eines fiskalisch-administrativen Molochs annahm - was lag näher, als den Glauben an die Realpräsenz Gottes und seiner Institutionen durch den Existenznachweis seines alter ego zu retten zu suchen, wie dies nicht zuletzt auch in der Reformation zum Tragen kam ${ }^{39}$.

Nur sollte der Anteil der Kirche an den Hexenverfolgungen in praxi nicht überschätzt werden: Die römische Inquisition kam, wie schon angedeutet, über bescheidene Anfänge nicht hinaus, zumal im Heiligen Römischen Reich, dem Zentrum der Verfolgungen, ihr Einfluß mit der Reformation ohnehin gebrochen war, auch in den altgläubigen Gebieten ${ }^{4}$. Hieraus erhellt, was nicht selten verkannt wird: Das Feld der Hexenprozesse wurde fast ausnahmslos von der weltlichen Strafrechtspflege der frühen Neuzeit bestellt, wobei der ideologische Hintergrund allemal christlicher Denktradition verpflichtet bleibt. Auch das Streben nach neuen, jetzt rationalen, Formen der Institutionalisierung in der frühen Neuzeit ist nicht zuletzt durch die Erfahrung der Ohnmacht - richtiger: die Abwehr derselben - diktiert, die der Zerfall des mittelalterlich-feudalen ordo ausgelöst haben muß ${ }^{4 I}$. Am greifbarsten wird diese >kollektive Traumatisierung` am Verhältnis des modernen Menschen zur Natur: Diese gerät der neuzeitlichen Ökonomie und Wissenschaft, namentlich der bürgerlich-kapitalistischen, primär zu einem Objekt der Ausbeutung und Beherrschung, wobei dieser Primat der Naturbeherrschung selbstredend nicht bei der äußeren Natur haltmacht, sondern auch die innere Natur des Menschen erfaßt, worauf schon Horkheimer/Adorno verwiesen haben ${ }^{42}$. Unter diesem Blickwinkel kulminierte in den Hexenprozessen das sadistische Ausagieren einer noch nicht in die Seelen und Körper integrierten Angst, wobei die Frau - in patriarchalischen Gesellschaften eine bevorzugte Repräsentanz von Trieb-Natur - fast schon zwangsläufig in das Zentrum des um die Natur geschlagenen Bannkreises projiziert würde.

Neueren Forschungsansätzen ist zuzugeben, daß über der Gleichförmigkeit der Prozeßabläufe gern die Vielfalt der Anlässe, die am Ausgangspunkt eines Prozesses standen, oder der Interessen, die mit der Inszenierung eines Prozesses verfolgt

$39 \mathrm{Zu}$ den sozialpsychologischen Folgerungen vgl. etwa Richter 1979.

40 Nicht einmal eine seit der ersten Hälfte des 17. Jhs. in Umlauf befindliche, $16 \$ 5$ im Druck erschienene römische Instruktion des Inhalts, daß das Prozedere in Hexensachen rechtswidrig erscheine, hatte urgendemen Einfluß auf die Prozesse, vgl. Zwetsloot 1954, 283 f.

${ }_{4} \mathrm{I}$ An diesem zentralen Ort hat $\mathrm{m}$. E. ein sozialpsychologisches Verständnıs des Wahns anzusetzen: inwieweit nämlich der Verlust eines externalisierten kollektıven Überıchs bei noch unzulänglicher Überich-Internalisıerung derartige Aggressionspotentiale Im Vereın mit projektıven Spaltungen der Mutter-Inago freisetzt. Zum Verhältnis von Angst und Aggression vgl. etwa Denker 1974. An dieser Stelle möchte ich die Gelegenheit wahrnehmen, auf ein womöglich bedeutsames psychohistorisches Detail aufmerksam zu machen: Ist schon zu fragen, ob die im Protestantismus zentrale Frage nach der ureıgenen Bezıehung zu Gott, die der altgläubigen Vermıttlungsınstanzen entbehrt, ein auch ökonomısch eigentümliches Verhältnis reflektıert, so begegnen innerhalb des Calvinismus höchst ungereımte Widersprüche: Von der Lehre, der ırdische, in erster Linıe ökonomisch verstandene, Erfolg indizıere gleıchsam, was man vom Jenseits zu erwarten habe, findet sich im Werk Calvıns keın Wort. Im Gegenteil stelit Calvıns Instıtutıo alleın auf die Prädestination ab, der durch ırdische Anstrengungen beizukommen von vornherein vergeblich sei. Daß ausgerechnet aus dieser zutiefst depressiven Ideologie mit dem Calvinismus der Vorreiter des Kapıtalismus erwachsen konnte, ist vorderhand befremdlich, doch klärt sich der Widerspruch, wenn man berücksıchtıgt, daß psychologisch einer der vornehmsten Abwehrmechanısmen der Depression, die in calvınıschen Hochburgen anzutreffende Ich-Stärke voraussetzt, in fast manischen Arbeitsrıtualen besteht. Daß der sich einstellende ökonomische Erfolg eıne Legıtımıerung erhesscht, versteht sich von selbst, nur ist die angesprochene calvinistusche Rationalisierung nicht ursprünglich calvınisch.

42 Horkheimer/Adorno 1969, passım oder Horkheimer 1967, 94. 
werden konnten, vernachlässigt werden ${ }^{43}$. So spielen Nachbarschaftsfehden fast regelmäßig eine Rolle beim Zustandekommen eines Verfahrens, konnte ein Hexenprozeß durchaus auch als Befriedungsstrategie bei Bevölkerungsunruhen dienen oder brach sich schlicht der Verfolgungswahn eines eifernden, mit der peinlichen Rechtspflege betrauten Juristen Bahn ${ }^{44}$. Zentrale Bedeutung für die Ubiquität des Anfangsverdachts in dörflichen Gemeinschaften kommt der landläufigen, agrarischer Produktionsweise womöglich inhärenten Vorstellung einer Art von >Güterkonstanz<zu, derentsprechend etwa der Abgang eines Stück Viehs den komplementären Zugewinn bei einem Dritten implizierte, vor welchem magischen Hintergrund naturgemäß jede(r) potentiell verdächtig erschien ${ }^{45}$. Über diese prozessualen Binnenstrukturen hinaus legen die Quellen - sofern man jedenfalls das Glück hat, nicht allein die stereotypen Prozeßprotokolle archiviert zu finden, sondern der Bestand auch Rückschlüsse auf die umfänglichen, formellen wie informellen Vorermittlungen und die dabei zutage getretenen Verdachtsmomente erlaubt - auch ein beredtes Zeugnis davon $a b$, in welch erdrückendem Ausmaß sich die Hexenprozesse den neuen Zeichen der Zeit, Triebunterdrückung und Affektstrangulierung, dem Kampf >Realitätsprinzips vs. Lustprinzip`, verschrieben hatten. So sehr kreiste die Verdachtschöpfung um die sogenannte >Sekundärtugenden< wie Verläßlichkeit, Arbeitsamkeit, maßvollen Lebensvollzug und geregelten Sexualhaushalt, daß deren Fehlen mit Fug einer ungeschriebenen Prozeßvoraussetzung gleichkam. Von daher kann man sich des Eindrucks nicht erwehren, als habe, parallel zur außereuropäischen Kolonialisierung, vermittels der Hexenprozesse auch eine innereuropäische Domestikations- und Disziplinierungskampagne dem Zivilisationsprozeß im Zuge der >Produktion des zuverlässigen Menschen ${ }^{46}$ blutigen Tribut gezollt.

Bei allen berechtigten Vorbehalten verallgemeinernden Erklärungen gegenüber, wie sie in neueren Publikationen erhoben werden: Wenn binnenstrukturelle Interpretationsansätze ihr Hauptaugenmerk auf die konkreten Entstehungsbedingungen und Prozeßverläufe richten, so ist darüber nachdrücklich in Erinnerung zu rufen, daß es sich allemal um einen Hexenprozeß mit all seinen Absonderlichkeiten handelte, der, aus was für Gründen auch immer, in Szene gesetzt wurde.

Und dieses Phänomen harrt - Heinsohn und Steiger, wie gezeigt, zum Trotz - nach wie vor einer zureichenden Klärung. Dabei soll gar nicht in Abrede gestellt werden, daß die in der Neuzeit einsetzende gesteigerte Diskriminierung von Empfängnisverhütung und Abtreibung in die Prozesse miteingeflossen ist, womit den Hexenverfolgungen für die Liquidation geburtenkontrollierender Techniken - so diese denn, wovon Heinsohn und Steiger ausgehen, zum gängigen Repertoire vormoderner Familienplanung zählten ${ }^{47}$ - durchaus entscheidende Bedeutung zukommt: Seit je in

43 Vgl. Lehmann in: Degn et al. (Hsg.) 1983 rof., wo sechs paradigmatusche Interpretationsmuster herausgearbeitet werden.

44 Gerade die Bedeutung des zuletzt erwähnten ssubjektiven` Faktors scheint mir über Gebühr vernachlässigt zu werden. In Nördlingen oder Esslingen kann keın Zweifel daran bestehen, daß durch die Intervention einzeiner Juristen ein latenter Wahn sich in so grauenhaften Pogromen manifestieren konnte, daß die Gemennwesen über Jahre hinweg terrorisıert wurden, ohne daß sich die Obrigkeit enzuschreiten getraute. Zumeist beendete erst der Tod des Hexenrichters die Verfolgungswelle.

45 Auf diese auf Foster 1965,292 ff. zurückgehende Theorıe des , limited good 1 m Sinne eines Nullsummenspiels hat unlängst auch Wunder in: Degn et al. (Hsg.) 1984, 189 verwiesen. Daß in den Hexenprozessen auch zweı kulturelle Diskurse, enn traditıonaler des Volks und en elaborıerter der Eliten, inemandergriffen, ist naheliegend, vgl. Muchembled 1982.

46 So der Titel enner Studie von Treiber/Stennert 1980 über die , Wahlverwandtschaft Fabrikdisziplin, dort S. 77 ff. auch en beachtlicher, Versuch, Foucault aus der mißlichen Lage des Kopfstands zu befresen; dem es gelingt, die ntcht selten ahıstorisch-fresschwebende Theoriebildung Foucaults zu entmystifizıeren.

47 Aus den überkommenen Quellen gewınnt man eher den Eindruck, als habe familienplanerısch die Kindstötung $1 \mathrm{~m}$ Vordergrund gestanden. Ob sıe die sultıma ratı< war, wie Heınsohn/Steıger i985, 38 
unmittelbarer Nähe zur Magie angesiedelt ${ }^{48}$, müßte es auch befremden, wenn Abtreibung und Empfängnisverhütung nicht in den Sog der Hexenprozesse geraten wären, zumal die in Hexensachen regelmäßig zur Verhandlung kommende Promiskuität auch die Abfolterung eines Geständnisses in punkto empfängnisverhütender oder abtreibender Praktiken tunlich erscheinen lassen konnte. Allein stand dies höchst selten einmal im Mittelpunkt oder auch nur am Ausgangspunkt eines Hexenprozesses und hatten die Pogrome weit mehr im Visier als die Ausrottung geburtenkontrollierenden Erfahrungswissens.

Der Forschung bleibt es also nicht erspart, auf die von Heinsohn und Steiger in schon dreister Manier zur Makulatur erklärten Interpretationsansätze etwa eines Elias, Lorenzer oder Foucault zurückzugreifen, will sie nähere Aufschlüsse über die Hexenverfolgungen gewinnen. Dabei verspricht insbesondere das Instrumentarium der analytischen Sozialpsychologie einen Zugang zu den psychohistorischen Mechanismen des Wahns zu eröffnen. So würde es mich nicht wundern, wenn in diesem Zusammenhang den Zerstückelungsphantasien, denen die Intuition Lacans, angeregt durch das visionäre Gemälde Hieronymus Boschs, für das Verständnis der psychischen Befindlichkeit des modernen Menschen eine Schlüsselrolle zugewiesen hat ${ }^{49}$, auch für das der Hexenprozesse, wo diese Phantasien am Objekt neugeborener Kinder in fast schon ritualisierter Form wiederkehren, konstitutive Bedeutung zukäme.

\section{Literatur}

Accursius 1612. Digestum Novum... Tomus Tertius... Commentariis Accursii Illustratus. Lugduni 1612.

Arndt et al. 1979. Arndt, C., Erhard, B., Funcke, L. (Hsg.): Der $₫ 218$ StGB vor dem Bundesverfassungsgericht. Heidelberg/Karlsruhe 1979.

Soldan/Heppe I9I I. Bauer, M. (Hsg.): Soldan/Heppe: Geschichte der Hexenprozesse, Bd. 1, 2 Hanau o.J. (Nachdruck der Ausgabe 191 $1^{3}$ ).

Becker 1977. Becker, G. et al.: Aus der Zeit der Verzweiflung. Zur Genese und Aktualität des Hexenbildes. Frankfurt a. M. 1977.

Berlich 1628. Berlich, M.: Quarta Pars Conclusionum Practicabilium Secundum ordinem Constitutonum Divi Augusti ... Lipsiae $1628^{3}$.

Böhm 1940, 194I, 1942. Böhm, E.: Der Schöppenstuhl zu Leipzig und der sächsische Inquisitionsprozeß im Barockzeitalter. In: ZStW 59, 1940, p.37Iss, 620ss; 60, I94I, p. I5sss; 61, 1942, p. 301 ss.

Degn et al. 1983. Degn, Ch., Schwann, H., Unverhau, D. (Hsg.): Hexenprozesse. Deutsche und skandinavische Beiträge. Neumünster 1983 .

Delumeau 1985 . Delumeau, J.: Angst im Abendland. Die Geschichte kollektiver Ängste im Europa des 14. bis 18. Jahrhunderts. Bd. I, 2, Reinbek 1985.

Denker 1974. Denker, R.: Angst und Aggression. Stuttgart 1974.

Diefenbach 1886 . Diefenbach, J.: Der Hexenwahn vor und nach der Glaubensspaltung in Deutschland, Mainz I 886.

Foster 1965. Foster, G.M.: Peasant society and the Image of Limited Good. In: American Anthropologist 67 (1965), $293 \mathrm{ff}$.

unterstellen, oder nıcht doch die sprıma ravoc, wofür die Fülle an Konzilbeschlüssen gegen das gemeınsame Nächtıgen von Kleınkındern und Eltern - morgens wurden dann die Kinder erdrückt aufgefunden - sprechen, wird nıcht mit hinreıchender Sicherheit auszumachen sein. Es fragt sıch freilich, weshalb, wenn doch laut Heınsohn und Steıger eın so ausgeklügeltes Empfängnısverhütungswissen zur Verfügung stand (ebd.), von der Kindstötung en so exzessiver Gebrauch gemacht wurde, worüber wir recht zuverlässig unterrichtet sind.

${ }_{4}^{8}$ Wie in Anm. 17 angedeutet, war schon $1 m$ römıschen Recht der magısche Charakter von Abtreibungsdrogen das Motiv, ihre Weitergabe unter Strafe zu stellen.

49 Lacan 1980,67 . 
Ginzburg 1980. Ginzburg, C.: Die Benandanti, Feldkulte und Hexenwesen im 16. und 17. Jahrhundert. Frankfurt a. M. 1980.

Haenel I 849. Haenel, G. (Hsg.): Lex Romana Visigothorum. Berolini 1849.

Hansen 1900. Hansen, J.: Zauberwahn, Inquisition und Hexenprozeß im Mittelalter. München 1900 .

Hansen 19or. Hansen, J.: Quellen und Untersuchungen zur Geschichte des Hexenwahns und der Hexenverfolgung im Mittelalter. Bonn $190 \mathrm{I}$.

Heinsohn 1984. Heinsohn, G., Steiger, O.: Die Vernichtung der weisen Frauen. In: Schröder, J. (Hsg.): Mammut, März Texte I \& 2 1969-1984, Herbstein 1984. p. 494-518.

Heinsohn/Steiger 1985. Heinsohn, G., Steiger, O.: Die Vernichtung der weisen Frauen. Hexenverfolgungen, Menschenproduktion, Kinderwelten, Bevölkerungswissenschaft. Herbstein 1985 .

Honegger 1978. Honegger, C.: Die Hexen der Neuzeit. Analyse zur anderen Seite der okzidentalen Rationalisierung. In: Honegger, C. (Hsg.): Die Hexen der Neuzeit. Frankfurt 1978, p. 2 Iff.

Horkheimer 1967. Horkheimer, M.: Zur Kritik der instrumentellen Vernunft. Frankfurt a. M. 1967.

Horkheimer 1969. Horkheimer, M., Adorno, Th. W.: Dialektik der Aufklärung. Frankfurt a. M. 1969.

Konstitutionen, kursächsische I 572 . Des Durchlauchigsten Hochgebornen... Augusten Hertzogen zu Sachsen... Verordnungen und Constitutionen, Dreßden I 578.

Kroeschell 1972, 1973. Kroeschell, K.: Deutsche Rechtsgeschichte, Bd. I (bis 1250), Reinbek 1972, Bd. 2 (1250 bis 1650 ), Reinbek 1973.

Kunze 1981. Kunze, M.: Der Prozeß Pappenheimer. Jur. Diss. München, Ebelsbach a. M. 1981. (Münchener Universitätsschriften - Juristische Fakultät - Abhandlungen zur rechtswissenschaftlichen Grundlagenforschung, Bd. 48).

Lacan 1980. Lacan, J.: Das Spiegelstudium als Bildner der Ichfunktion wie sie uns in der psychoanalytischen Erfahrung erscheint. In: Lacan, Schriften I, 6r ff.

Lehmann 1983. Lehmann, H.: Hexenprozesse in Norddeutschland und in Skandinavien im 16., 17. und 18. Jahrhundert. Bemerkungen zum Forschungsstand. In: Degn, Ch. et al. (Hsg.) $1983,9 \mathrm{ff}$.

Lorenzer 1984. Lorenzer, A.: Intimität und soziales Leid. Archäologie der Psychoanalyse. Frankfurt a.M. 1984 .

Magnum Bullarium Romanum. Editio novissima, T. 2. Lugduni 1673.

Menochius 1585 . Menochius, J.: . . omnia ... opera in ins canonıcum et cruile... T. I. Lugduni Is 85 .

Midelfort 1972. Midelfort, E.H. C.: The Witch Hunting in Southwestern Germany. Stanford 1972.

Muchembled 1982. Muchembled, R.: Kultur des Volks-Kultur der Eliten. Stuttgart 1982.

Murray 1962. Murray, M.: The Witch-Cult in Western Europe. Oxford $1962^{2}$.

Oldenburger 1675. Oldenburger, Ph. A.: Thesaurı Rerumpublicarum Pars Quarta. Genevae 1675 .

Radbruch/Kaufmann 1975. Radbruch, G., Kaufmann, A. (Hsg.): Die Peinliche Gerichtsordnung Karls V. von 1532. Stuttgart $1975^{4}$.

Raymund von Peniafort r603. Raymund von Peniafort: Summa Su Raymundi de Peniafort Barcinonenis... de Poenitentia... cum glossis Joannis de Friburgo. Romae 1603.

Richter 1979. Richter, H. E.: Der Gotteskomplex. Reinbek 1979.

Sanchez 1614, 1706. Sanchez, Th.: Disputationum de Sancto Matrimonii Sacramento Tom tres. T. 3. Antwerpiae 1614; Norimbergae 1706.

Schmidt, I94I. Schmidt, E.: Inquisitionsprozeß und Rezeption. In: Festschrift für Heinrich Siber. Leipzig $1941,97 \mathrm{ff}$.

Schormann I98r. Schormann, G.: Hexenprozesse in Deutschland. Göttingen I 98 I.

Schott 1982. Schott, C.: Besprechung zu Schormann, G.: Hexenprozesse in Deutschland, Göttingen 1981. In: ZfNR 1982 (I, 2), $68 \mathrm{f}$.

Sprenger I 574,1674 . Sprenger, J., Institoris, H.: Malleus Maleficarum, Venetiís I $574,1674$.

Sprenger I 983 . Sprenger, J., Institoris, H.: Der Hexenhammer, (Malleus maleficarum). Übersetzt von Schmidt, J. W. R.. München $1983^{2}$.

Stockinger 1984. Stockinger, L.: Invidia Curiositas und Hexerei. Hexen- und Teufelsglaube in literarischen Texten des 17. Jahrhunderts. In: Degn et al. 1984, $28 \mathrm{ff}$.

Stolleis 1985 . Stolleis, M.: Aufgabe der neueren Rechtsgeschichte oder: Hic leones. In: Rechtshistorisches Journal 4 (1985), $251 \mathrm{ff}$. 
Treiber 1980. Treiber, H., Steinert, H.: Die Fabrikation des zuverlässigen Menschen. Über die "Wahlverwandtschaften « von Kloster- und Fabrikdisziplin. München I980.

Trusen 1962. Trusen, W.: Anfänge des gelehrten Rechts in Deutschland. Ein Beitrag zur Geschichte der Frührezeption. Wiesbaden 1962.

Trusen 1984. Trusen, W.: Strafprozeß und Rezeption. Zu den Entwicklungen im Spätmittelalter und den Grundlagen der Carolina. In: Landau, P., Schroeder F. Ch. (Hsg.): Strafrecht, Strafprozeß und Rezeption. Grundlagen, Entwicklung und Wirkung der Constitutio Criminalis Carolina. Frankfurt a. M. 1984 , p. $29 \mathrm{ff}$.

Unverhau 1984. Unverhau, D.: Akkusationsprozeß-Inquisitionsprozeß. Indikatoren für die Intensität der Hexenverfolgung in Schleswig-Holstein. In: Degn et al. I984, S. $59 \mathrm{ff}$.

Weng, J.F.: Die Hexenprozesse der ehemaligen Reichsstadt Nördlingen in den Jahren 1590-I 594. In: Ders., Guth, J. B. (Hsg.): Das Ries wie es war und ist. 6. Heft, sff.; 7. Heft, 3 ff. Nördlingen o.J.

Wieacker 1967. Wieacker, F.: Privatrechtsgeschichte der Neuzeit. Göttingen 1967.

Wunder 1984. Wunder, H.: Hexenprozesse im Herzogtum Preußen während des I6. Jahrhunderts. In: Degn et al. 1984, $179 \mathrm{ff}$.

Zwetsloot 1954. Zwetsloot, H.: Friedrich von Spee und die Hexenprozesse. Trier 1954.

\section{Gerd Winter \\ Über Pflöcke im wandernden Rechtsboden}

Die Eigentumskonzeption des Bundesverfassungsgerichts und Ferdinand Lassalles Theorie erworbener Rechte

Die schleichende Vergiftung von Luft, Gewässern, Grundwasser und Boden, die langsame Erwärmung der Atmosphäre und Ausdünnung der Ozonschicht, die schlafenden Unfallrisiken von Kernkraftwerken, Chemieanlagen und Abfalldeponien, die schrittweise Vernutzung von naturnahen Flächen - immer häufiger wird das Sukzessive zur offenbaren Katastrophe, zum Waldsterben, zu abrutschenden Hängen, wirklichen Großunfällen, deren Frequenz die gesellschaftlichen Verdrängungsmechanismen in Zeitnot bringt. Die ökonomischen, politischen und kulturellen Strukturen, die auf die Vermehrung der ungeheuren Warenansammlung gerichtet sind, müssen umgebaut werden, wenn sie ihre natürliche Basis nicht verlieren sollen. Tiefgreifendem Wandel stellen sich aber erworbene Rechte entgegen - Kapital und Arbeit sind investiert worden, Genehmigungen sind auf Dauer erteilt, für Eingriffe wird Entschädigung verlangt -, und sie müssen überwunden werden, wenn der Übergang gelingen soll. In solcher Situation stellt sich die Frage, ob die Eigentumsgarantie auf das Problem vorbereitet ist, und es ist aufschlußreich zu vergleichen, wie frühere Übergänge bewerkstelligt worden sind.

\section{I.}

Blickt man aus dieser Perspektive auf die Eigentumskonzeption des Bundesverfassungsgerichts, so könnte die Untersuchung zum Loblied insbesondere auf den Naßauskiesungsbeschluß des Ersten Senats geraten. ' Zurechtgewiesen der Bundesgerichtshof, abgelehnt seine »Umschlagtheorie« (Böhmer), nach der allzuviel »So-

I BVerfG v. I5.7. 1981, E 58, 300 . 